\title{
Causal Relations among Executive Functions and Academic Skills from Preschool to End of First Grade
}

\author{
Neeltje J. Davidse ${ }^{1}$, Maria T. de Jong ${ }^{1}$ \& Adriana G. Bus ${ }^{1}$ \\ ${ }^{1}$ Department of Education and Child Studies, Leiden University, PO Box 9555, 2300 RB Leiden, The Netherlands \\ Correspondence: Adriana G. Bus, Department of Education and Child Studies, Leiden University, PO Box 9555, \\ 2300 RB Leiden, The Netherlands. Tel.: 31-71-527-1850 E-mail: bus@fsw.leidenuniv.nl \\ Received: May 14, 2014 \\ Accepted: March 19, 2015 \\ Online Published: March 20, 2015 \\ doi:10.5430/elr.v4n1p49 \\ URL: http://dx.doi.org/10.5430/elr.v4n1p49
}

\begin{abstract}
In a sample of 87 children we tested whether executive functions (memory and inhibition) in preschool predict numeracy and literacy skills in first grade. We controlled for variation attributable to school level, several covariates, and preschool academic skills. The long-term findings indicated that early delays in executive functions are often temporary and not strong predictors of academic skills in Grade 1. Relating changes in executive functions to changes in numeracy and literacy skills, using a fixed effects analysis, we found support for the hypothesis that executive functions are causally related to academic skills. What this may mean and implications of this finding for the school curriculum and interventions are discussed.
\end{abstract}

Keywords: Executive functions, Academic skills, Longitudinal, Fixed effect analysis, Literacy, Math, Memory, Inhibition

\section{Introduction}

\subsection{Executive Functions and Academic Achievement}

Executive functions (EF) are a commonly used umbrella term for a set of interrelated cognitive processes that are required in planning and problem solving (Diamond, 2013). Components of executive functions are 1) inhibition and attention control (i.e., staying focused for a period thereby ignoring distractors), 2) the ability to retain information and manipulate information, referred to as short-term memory and working memory, and 3) cognitive flexibility, referring to the ability to change perspectives and search for new problem solutions if necessary (e.g., Blair, Zelazo, \& Greenberg, 2005; Davidson, Amso, Anderson, \& Diamond, 2006; Diamond 2013;Diamond \& Lee, 2011). Early EF skills relate to early numeracy and literacy (e.g., Davidse, de Jong, Bus, Huijbregts, \& Swaab, 2011; Duncan et al., 2007; Kegel, van der Kooy-Hofland, \& Bus, 2009; Kroesbergen, Van Luit, Van Lieshout, Van Loosbroek, \& Van de Rijt, 2009; McClelland et al., 2007; NICHD, 2003; Welsh, Nix, Blair, Bierman, \& Nelson, 2010), and predict later math and literacy development (Blair \& Razza, 2007; Bull, Espy, \& Wiebe, 2008), even when controlling for earlier academic skills (Duncan et al., 2007). For instance, when children are easily distracted, instruction in kindergarten and first grade may be less effective, as a result of which children may lag behind in alphabetic skills after being in kindergarten and first grade for three months (Kegel \& Bus, 2013).

Studies on the effects of EF on numeracy and literacy development have focused on preschool and kindergarten (e.g., Blair \& Razza, 2007; Foy \& Mann, 2013; McClelland et al., 2007; Kegel \& Bus, 2014; Welsh et al., 2010) or on math and reading development from Grade 1 upwards (e.g., Altemeier, Abbott, \& Berninger, 2008; Mazzocco \& Kover, 2007; Toll, Van der Ven, Kroesbergen, \& Van Luit 2011), with time spans ranging from half a year to two years. Some studies examine the effects of EF at one particular point in time (e.g., Davidse et al, 2011; Espy et al., 2004; Kroesbergen et al., 2009). Based on longitudinal studies, it is argued that preschool EF skills are causally related to later academic outcomes (Raghubar, Barnes, \& Hecht, 2010). Studies that relate early EF skills to later academic skills (commonly measured later in preschool or in kindergarten) (e.g., Blair \& Razza, 2007; Bull, Espy, \& Wiebe, 2008; Clark, Pritchard, \& Woodward, 2010), do not control for early academic skills (Blair \& Razza, 2007; Clark et al., 2010; Raghubar et al., 2010), or do not take into account possible environmental effects (Blair \& Razza, 2007; Bull et al., 2008). In fact, positive relations among early EF skills and later academic skills might be spurious when outcomes are not corrected for potentially relevant covariates (Willoughby, Kupersmidt, \& Voeger-Lee, 2012). A potentially relevant covariate may, for instance, be the educational level of the parents because that relates to 
counting and reading activities in preschool age (e.g., Davidse et al., 2011; LeFevre et al., 2009) but simultaneously to the development of EF (NICHD, 2003).

Another complicating factor may be that studies do not take into account that executive functions develop rapidly during early childhood (McClelland, Acock, \& Morrison, 2006; McClelland et al., 2007). Even though attention is rather stable it develops until the age of 6-8 (Posner \& Rothbart, 2000), and inhibition, switching, and memory skills develop well into adulthood (Davidson et al., 2006; Diamond, 2013; Gathercole, Pickering, Ambridge, \& Wearing, 2004). Changes in EF may therefore be a more reliable indicator than measurements at one particular point in time. Although the conclusion is commonly drawn that children entering preschool with low EF and/or emergent academic skills are at risk of experiencing difficulties in learning to read, write, and solve sums, these children's EF skills might improve during kindergarten (McClelland et al., 2007), which might explain why EF skills do not predict learning to read, write, and solve math problems in Grade 1. In other words, even when preschool EF do not relate to math, reading, and writing in Grade 1, we might find relations when we take into account that EF skills may be rapidly changing. If changes in $\mathrm{EF}$ relate to changes in academic skills, there is strong evidence for the conclusion that EF and academic skills are causally related (McClelland et al., 2007; Raghubar et al., 2010; Willoughby et al., 2012). Over a short period (time span between pre- and posttest was on average 4.4 months) Willoughby et al., (2012) demonstrated, for a sample of children aged 3.1 to 5.8, that relations among changes in EF skills and academic skills were non-significant suggesting that there is no causal relationship between academic skills and EF. A replication in our laboratory in a group of older children (mean age 61 months at pretest), with a one-year time span and other EF tests (Kegel \& Bus, 2014), revealed, however, that changes in EF were related to changes in literacy development suggesting a causal relation between EF and literacy development.

A longer time span may result in greater variability in change and may provide a stronger test of the effect of EF development on academic development (Willoughby et al., 2012). We therefore extended a previous study by testing long-term effects of EF development on numeracy and literacy development over two-and-half years, from preschool (when children were on average 55 months old) to end of first grade (when children were on average 83 months old). As far as we know there are no studies available predicting academic growth from changes in EF in the course of preschool to first grade. We focused on two core EF skills, memory and inhibition, because both skills develop earlier than a third core EF skill, cognitive flexibility (Diamond, 2013).

The first main goal was to test whether preschool EF skills (short-term memory and inhibition) are related to math, reading, and writing skills in preschool and in Grade 1. We controlled for age, gender, and education of the mother, and in the long-term tests, also for preschool numeracy and literacy skills because those are moderate to strong predictors of later academic achievement (Jordan, Kaplan, Nabors Oláh, \& Locuniak, 2006; Muter, Hulme, Snowling, \& Stevenson, 2004; Raghubar et al., 2010; Storch \& Whitehurst, 2002). For this purpose we executed regression analyses predicting academic skills in preschool and first grade, thereby controlling for variation attributable to school.

The second main goal was to test whether, over a three year time span, changes in EF are related to changes in academic development. For this purpose, we applied Fixed Effects Analysis (FEA) to a repeated measures design (Twisk, 2006; Willoughby et al., 2012). We hypothesized that a relation between EF development and numeracy and literacy development may exist, even when there is no direct relation between preschool EF and academic achievement in Grade 1. EF may be low at the start of preschool but improve during preschool and first grade, thereby no longer being a predictor of growth in reading and math (Bodrova \& Leong, 2007; Burrage et al., 2008). Previous findings suggest that the effects of EF on numeracy development are stronger compared to the effects of EF on literacy development (Blair \& Razza, 2007; Duncan et al., 2007; McClelland et al., 2007). We tested this hypothesis by including both numeracy and literacy development.

In a repeated measures design, the best solution is to apply exactly the same emergent academic and EF tests at the first and second assessment. Unfortunately it is impossible to apply the same tests in preschool and Grade 1, because target skills can only be measured within a brief period to avoid non-normal distributions due to floor and ceiling effects (Paris, 2005; Paris \& Luo, 2010). Using the same tests in preschool and Grade 1 would lead to ceiling effects in Grade 1 (Paris, 2005; Paris \& Luo, 2010), and, vice versa, testing Grade 1 skills in preschool would result in floor effects. The best indicator of working memory, a digit span backwards task, for instance, could be applied in first grade but appeared to be too difficult for 4-year-olds in our study and previous ones (Bull et al., 2008). In preschool we therefore applied the digit span forward task, measuring short-term memory, which is considered to be a precursor of working memory (Diamond, 2013). To assess inhibition, we used different age-appropriate tests in preschool and Grade 1. In preschool in addition to short-term memory and inhibition, we measured two early literacy 
skills (phonological awareness with a rhyming task and emergent writing with a dictation task) and number sense tasks, which are moderate to strong predictors of conventional math, reading, and writing skills (Jordan et al., 2006; Muter et al., 2004; Storch \& Whitehurst, 2002). To assess Grade 1 math we tested children's ability to solve simple problems. Literacy skills were assessed by a word dictation and a word reading test. To be able to compare scores on pre- and posttest, all test scores were standardized.

\section{Method}

\subsection{Participants}

Participants were 87 children with a native Dutch background. The sample was recruited from 7 randomly selected schools in the western part of the Netherlands. The schools were attended by Dutch-speaking children from lower- to middle class families. The study was carried out after informed parental consent was received. For the first time of testing, children who had just started preschool were selected (age range 52 to 58 months; mean age was 54.52 months; $S D=1.95$ months). These children were tested again slightly more than two years later at the end of Grade 1 . Mean age at the second time of testing was 82.75 months ( $S D=2.90$ months; range 72 to 89 months). In preschool, four of the 87 children refused to participate, resulting in 83 participants ( 38 boys and 45 girls) who completed the measurements at both times.

\subsection{Educational Level of the Mother}

Mothers reported their highest level of education on a seven-point-scale ranging from primary education to university degree.

\subsection{Preschool Numeracy Skills}

Counting principles. This task, adapted from Geary, Hoard, and Hamson (1999), assessed children's ability to detect violations of the counting principles: One-to-one correspondence, order irrelevance and abstraction. The child was first introduced to a puppet that was just learning how to count and needed assistance. White and black checkers were used for counting. In part of the trials, the total amount counted by the puppet was incorrect. After each trial the experimenter therefore asked: "Did he count correctly? Show how you would count the stones." This task consisted of a total of eight items to assess the child's understanding of one-to-one correspondence $(n=4)$, order irrelevance $(n$ $=2)$, meaning that you can count not only from left to right, but also in random order ignoring features like color $(n$ $=2$ ). Based on the child's answers: 1) whether the puppet counted correctly, and 2) whether the number of checkers counted by the child equaled the actual number of checkers, a score was allocated relating to whether the child was familiar with the counting principle assessed (max score was 8). Percentage correct was calculated.

Number knowledge and magnitude comparison. In the number knowledge task adapted from Griffin (2002), children were asked: "Which number comes before five?" or "Which number comes after seven?" We also assessed magnitude comparison by asking: "I will say two numbers, can you tell me which one is bigger: nine, two.", or by asking: "Which number is smaller: Four, three?" This task consisted of a total of four items. Percentage correct was calculated.

Conservation principles. We assessed whether children understood that the total number of a set remains the same after rearranging the items without adding or removing items. The experimenter counted a row of checkers (rows of four, six, eight, and nine checkers, respectively) and then split the row into two parts and asked the child: "How many stones are here together" (circling her finger around all the checkers). The same was done the opposite way (rows with five, seven, eight, and nine checkers respectively). In all, this task consisted of eight items. Percentage correct was calculated.

Estimation. In this task, adapted from Jordan and colleagues (2006), children were shown five cards with 3, 8, 15, 25, or 35 dots placed haphazardly on each card. The cards were presented to the child in the above order so that the number of dots increased each time they were shown a new card. The experimenter briefly showed each card and said: "About how many dots do you see?". The child received the score of 1 if he or she estimated within $25 \%$ of the actual number of dots on the card. The maximum number of points was five. Percentage correct was calculated.

Number naming. On a computer screen, children were shown numbers from 0 to 20 , one at a time, in the following order: 1, 13, 4, 17, 2, 11, 8, 14, 20, 5, 16, 3, 12, 6, 0, 19, 7, 15, 9, 18, and 10. After 4 seconds, the next number was automatically presented. Children were instructed to name the numbers as soon as possible. Percentage correct was calculated.

Non-symbolic and symbolic addition and subtraction sums. This task was adapted from Jordan and colleagues (2006). In the non-symbolic condition, children were able to use material (checkers) to solve the sums. The 
experimenter said for example: "Look, I have two stones. Now I'm covering them. Watch carefully, I'm adding one stone. How many stones do I have now? Show it to me by using your stones and then tell me the number." The addition as well as the subtraction sums had one practice item where the experimenter corrected the child if needed. A total of four addition $(2+1 ; 4+3 ; 2+4 ; 3+2)$ and four subtraction sums $(3-1 ; 7-3 ; 5-2 ; 6-4)$ were used. In the symbolic condition, exactly the same sums were presented, but this time in a story context. Children were not allowed to use the checkers to solve the sums. The experimenter asked for example: "Mary has six bananas, Joe takes away four bananas. How many bananas does Mary have now?" For both tasks percentage correct was calculated.

Composite measure: number sense. A composite measure of the scores on all the early numeracy subtests was calculated by adding scores on the early numeracy subtests in percentages and dividing the total score by the number of subtests (e.g., Jordan, Kaplan, Locuniak, \& Ramineni, 2007). This resulted in a mean correct score on number sense in percentages. Alpha reliability over all subtests equaled .70 .

\subsection{Preschool Literacy Skills}

Emergent writing. Children were asked to write down their proper name and the words mama [mum], vuur [fire], kaas [cheese], wiel [wheel], and boot [boat]. The writings were scored based on a scale ranging from 0 (scribble) to 13 (conventional spelling); see Levin \& Bus (2003) for a detailed description. The writing scores were summed, resulting in a total score on emergent writing (max score is 78). Intercoder agreement ranged from .80 (cheese) to .91 (wheel). Any disagreement was resolved through discussion. Alpha reliability equaled .91.

Rhyming. On a computer screen one picture appeared (for example a picture of a hand), and simultaneously the question: "Which word rhymes with hand [Dutch word for hand]?" is read aloud by the computer. Next, three pictures appeared in succession and the name of the object was simultaneously read aloud (for example, kast [cupboard], mand [basket], vaas [vase]. The child's task was to name or point to the rhyming word (in this example mand [basket]. One practice trial and 10 test trials were presented. The score equaled the number of correct responses (max score is 10). Alpha reliability equaled .83 .

\subsection{Preschool Executive Functions}

Short-term memory. The 'Digit span forward task' from the Kaufman Assessment Battery for Children (Kaufman \& Kaufman, 1983) was used as an indicator of short-term memory. In this task, the child repeated numbers in exactly the same order. The test started with one practice item of two numbers similar to the first level and increased with one number every next level (three items per level). The test was discontinued if a child made an error in two consecutive items of the same length. The score equaled the number of correct responses.

Inhibition. Peg tapping (Diamond \& Taylor, 1996) was included as indicator of inhibition. When the experimenter tapped once, the child had to tap twice and vice versa, thereby inhibiting his or her natural response to mimic the experimenter's behavior. The task consisted of 16 items. Alpha reliability equaled .85 . The total score equaled the number of correct responses.

\subsection{Grade 1 Math Skills}

Math skills in Grade 1 were tested using the DLE Test for Mental Arithmetic, a standardized test (De Vos, 2001). Children receive a two-sided form with a total of 200 addition, subtraction, multiply, and division sums of increasing difficulty up to 100 . The test starts with sums up to 10 . Within 3 minutes, children need to solve as many sums as possible and skipping sums is not allowed. The score is the total of correct sums minus the incorrect ones. Alpha reliability reported in the manual is .96 (De Vos, 2001).

\subsection{Grade 1 Literacy Skills}

Dictation. Children were asked to write down 7 Dutch words: Spiegel [mirror], gezicht [face], schommel [swing], inktvis [inkfish], knecht [farm-hand], dolfijn [dolphin], and borstel [brush]. These words were chosen, because of their variety in orthography. A correctly spelled word equaled 3 points. For each error, one point was subtracted. The maximum score equaled 21. Alpha reliability equaled .95 .

Word reading. A standardized one-minute word reading test was administered to assess word reading skills (Brus \& Voeten, 1973). Within one minute, words have to be read aloud from a list containing 116 words. The score equaled the number of correct responses minus the incorrect ones. 


\subsection{Executive Functions in Grade 1}

Working memory. The subtest digit span backwards of the WISC-III (Wechsler, 1992) was administered to assess working memory. The test starts with repeating two digits and in every level the number of digits increases with one. The child is asked to repeat the digits in reverse order. The total score equals the number of correct responses (max. 14).

Inhibition/switching. The Dimension Change Cart Sort Task (Zelazo, 2006) was used as an indicator of inhibition and switching abilities. Cards contain a red truck, a blue truck, a red star or a blue star. In the first part, children have to sort the cards by color, in the second part by figure (half of the children started with the 'figure condition'). The test consists of 12 cards, either with or without a black border. Children are instructed to play the color game when a card contains a border and the figure game when cards have no border. When showing a card, the experimenter only mentions whether the card is with or without a border. The score equaled the number of correct responses in the test condition. For a detailed description see Zelazo (2006). We had missing data on this test for 30 children, because some experimenters made mistakes in applying the test. Alpha reliability equaled .73 .

\subsection{Procedure}

After the schools' principals agreed, parents received a flyer from the first author with information about the purpose of the study and the procedure (number of sessions, activities during the sessions, etc.). The phone number and e-mail address of the first author were also provided in case parents wished additional information. Parents signed a written consent for participation.

All measures were individually administered in a spare room at school by the first author or one of seventeen trained bachelor and master students. The preschool tests were spread over six sessions of about 15-20 minutes. Session order was counterbalanced between participants whereas the order of tasks within a session was fixed. Testing took place at the end of Grade 1 in one session lasting about 40 minutes. All sessions were videotaped by a digital camera in a fixed position, which enabled a check on the quality of testing and coding. Due to technical problems, the score on the number naming task of one child is missing as well as four children's score on Mental Arithmetic. Therefore $N$ varies somewhat across analyses.

\subsection{Data analysis}

In the first two sets of analyses, we used Huber-White estimates to correct for the non-independence of observations within schools $(N=6)$. The estimates were included in the Complex Sample General Linear Model (CSGLM, SPSS 19). Next, a Fixed Effect Analysis (FEA) was carried out regressing changes in academic achievement on changes in EF.

The first set of models regressed preschool academic achievement (number sense, rhyming, or emergent writing) on preschool EF (short-term memory or inhibition) and demographic covariates (age, gender, educational level of the mother). The second set of models regressed Grade 1 academic achievement (math, reading, or writing) on preschool EF (short-term memory or inhibition), demographic covariates, and preschool academic achievement. By using repeated measures data for EF and academic skills in the third set of models, all measured and unmeasured time-invariant child characteristics that may confound the association between executive functions and academic skills were automatically controlled. The FEA model takes into account that observations are clustered within children by including a random intercept:

$$
\begin{aligned}
& \text { Academic skills }_{\mathrm{ij}}=\beta_{0 \mathrm{ij}}+\beta_{1} \text { (executive functions }_{\mathrm{ij}} \text { ) } \\
& \beta_{0 \mathrm{ij}}=\gamma_{00}+\mathrm{u}_{0 \mathrm{j}}+\mathrm{e}_{0 \mathrm{ij}} \\
& \gamma_{00}=\text { average intercept } \\
& u_{0 j}=\text { unexplained deviation from average intercept } \gamma_{00} \text { for child } \mathrm{j} \\
& e_{0 i j}=\text { residual error }
\end{aligned}
$$

The slope may vary as well between children and should be allowed to be random, implying that instead of a fixed effect for EF $\left(\beta_{1 *} \mathrm{EF}_{\mathrm{ij}}\right)$ we have to add an interaction between EF and child to the model $\left(\beta_{1 \mathrm{j} *} \mathrm{EF}_{\mathrm{ij}}\right)$. As a next step, intercept and/or slope were allowed to differ between schools as well. Likelihood ratio tests were applied to evaluate whether or not random intercepts for school or random slopes for individuals and school should be considered. Results for the best fitting models are presented in Tables 4.2 and 4.3.

In order to establish a common metric for interpreting all of the results, achievement and EF measures were standardized. Hence, unstandardized regression coefficients for EF measures represent the amount of change in 
achievement (in standard deviation units) that result from a hypothesized one standard deviation unit change in EF.

\section{Results}

\subsection{Correlations and Descriptive Statistics}

Table 1 shows descriptive statistics and correlations among variables. Preschool EF skills were significantly related to the preschool academic skills: numbers sense, rhyming, and emergent writing. With the exception of the significant correlation between preschool inhibition and Grade 1 mathematics, preschool EF skills did not correlate with Grade 1 academic skills. Academic skills in preschool correlated significantly with academic skills in Grade 1. Due to the great variability early in EF development, preschool EF skills did not correlate with Grade 1 EF skills. All preschool academic skills correlated moderately, likewise all Grade 1 academic skills correlations were moderate to strong.

Table 1. Descriptive statistics and correlations among variables

\begin{tabular}{|c|c|c|c|c|c|c|c|c|c|c|c|}
\hline & \multirow[b]{2}{*}{$\begin{array}{l}\text { Test } \\
(N=83)\end{array}$} & \multicolumn{5}{|c|}{ Preschool } & \multicolumn{5}{|c|}{ Grade 1} \\
\hline & & Mean $(S D)$ & Inhibition & $\begin{array}{l}\text { Number } \\
\text { sense }\end{array}$ & Rhyming & $\begin{array}{c}\text { Emergent } \\
\text { writing }\end{array}$ & $\begin{array}{l}\text { Working } \\
\text { memory }\end{array}$ & Inhibition & Math & $\begin{array}{c}\text { Word } \\
\text { Reading }\end{array}$ & Dictation \\
\hline \multirow[t]{5}{*}{ Preschool } & $\begin{array}{l}\text { Short-term } \\
\text { memory } \\
(N=83)\end{array}$ & $\begin{array}{c}6.76 \\
(1.81)\end{array}$ & .09 & $.28 *$ & $.36^{*}$ & $\begin{array}{c}.20 \\
(p=.07)\end{array}$ & .08 & .24 & -.04 & .13 & .20 \\
\hline & $\begin{array}{l}\text { Inhibition } \\
(N=83)\end{array}$ & $\begin{array}{l}13.15 \\
(2.95)\end{array}$ & - & $.37 * *$ & $.37 * *$ & $.29^{*}$ & .08 & .17 & $.35 *$ & .15 & $\begin{array}{c}.25 \\
(p=.07)\end{array}$ \\
\hline & $\begin{array}{l}\text { Number } \\
\text { sense }(\% \\
\text { correct) } \\
(N=83)\end{array}$ & $\begin{array}{c}43.33 \\
(10.10)\end{array}$ & & - & $.53 * *$ & $.42 *$ & .17 & .22 & $.40 * *$ & $.29 * *$ & $.34 * *$ \\
\hline & Rhyming & $\begin{array}{c}7.42 \\
(2.73)\end{array}$ & & & - & $.34 * *$ & $.23 *$ & .21 & $\begin{array}{c}.21 \\
(p=.06)\end{array}$ & $.34 * *$ & $.35^{* * *}$ \\
\hline & $\begin{array}{l}\text { Emergent } \\
\text { writing } \\
(N=83)\end{array}$ & $\begin{array}{c}46.61 \\
(12.54)\end{array}$ & & & & - & .07 & .16 & $.35^{* *}$ & $.35 * *$ & $.45^{* *}$ \\
\hline \multirow[t]{5}{*}{ Grade 1} & $\begin{array}{l}\text { Working } \\
\text { memory } \\
(N=83)\end{array}$ & $3.61(1.06)$ & & & & & - & .24 & $.28^{*}$ & $.26^{*}$ & $.27^{*}$ \\
\hline & $\begin{array}{l}\text { Inhibition } \\
(N=53)\end{array}$ & $\begin{array}{c}8.50 \\
(2.59)\end{array}$ & & & & & & - & .16 & $\begin{array}{c}.24 \\
(p=.09)\end{array}$ & $\begin{array}{c}.25 \\
(p=.08)\end{array}$ \\
\hline & $\begin{array}{l}\text { Math } \\
(N=83)\end{array}$ & $\begin{array}{l}17.86 \\
(6.56)\end{array}$ & & & & & & & - & $.49 * *$ & $.48^{* *}$ \\
\hline & $\begin{array}{l}\text { Reading } \\
(N=83)\end{array}$ & $\begin{array}{c}30.12 \\
(15.08)\end{array}$ & & & & & & & & - & $.63 * *$ \\
\hline & $\begin{array}{l}\text { Dictation } \\
(N=83)\end{array}$ & $\begin{array}{l}16.29 \\
(2.64)\end{array}$ & & & & & & & & & - \\
\hline
\end{tabular}

Memory. As can be deduced from preschool results (see Table 2), short-term memory in preschool was significantly related to the overall measure of number sense $(B=.32 ; p<.05)$ and to rhyming $(B=.27 ; p<.05)$. Emergent writing however revealed a different pattern: Preschool short-term memory was not related to preschool emergent writing.

Grade 1 outcomes showed a decrease in the association between short-term memory and academic skills. After controlling for preschool number sense skills $(B=.45 ; p<.001)$, preschool short-term memory was not significantly related to solving math problems. Likewise, preschool short-term memory was not related to Grade 1 reading and writing when controlling for a marginal effect of preschool rhyming $(B=.40 ; p=.08)$ and a significant effect of emergent writing $(B=.19 ; p<.05)$.

However, applying a Fixed Effects model (differences) revealed significant effects of EF on academic skills. Development in memory skills between preschool and Grade 1 were significantly related to developmental changes in math over the same period $(B=.27 ; p<.01)$, and likewise to changes in reading $(B=.26 ; p<.001)$ and in writing $(B=.15 ; p<.05)$. According to the log-likelihood tests, a random slope did not result in model fit improvement in any of the models relating memory to academic development. Therefore, a random slope was not included. School as a random intercept or slope in addition to subject did not improve the models relating memory development to academic development and was therefore not included as a random factor. Outcomes for the models with the best fit are presented in Table 2. 
Table 2. Regression coefficients relating math, reading, and writing to memory

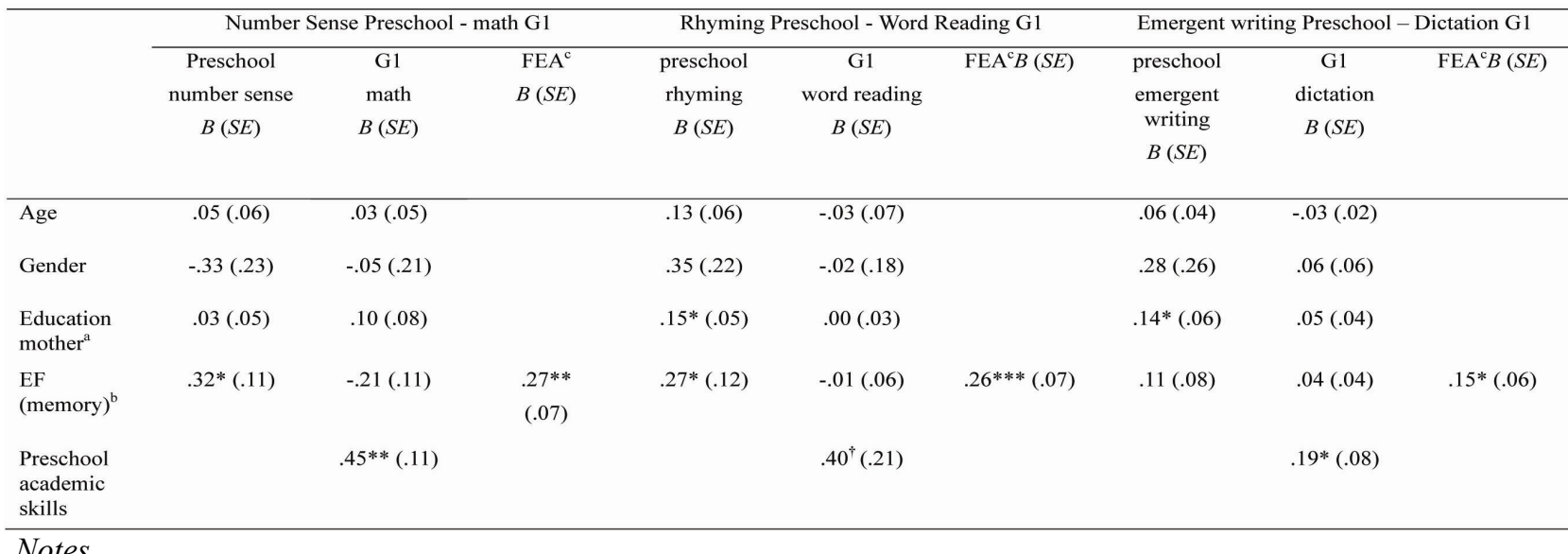

${ }^{a}$ Education $=$ highest educational level of mother (ranging from 1 to 7 ).

${ }^{\mathrm{b}}$ Using preschool score (short-term memory) as predictor of preschool and Grade 1 literacy outcomes but using memory development (short-term memory preschool - working memory Grade 1) when predicting difference in literacy outcomes.

${ }^{\mathrm{c}}$ Fixed Effect Analysis.

$* p<.05 ; * * p<.01 ; * * * p<.001 ;{ }^{\dagger} p=.08$

Inhibition. At preschool, inhibition was significantly related to number sense when controlling for background variables $(B=.38 ; p<.05)$ but it was not significantly related to emergent writing and rhyming (see Table 3 ).

Preschool inhibition did not predict Grade 1 academic outcomes after controlling for background variables and significant effects of preschool number sense skills $(B=.41 ; p<.01)$, preschool rhyming $(B=.37 ; p<.05)$, and a marginally significant effect of emergent writing $(B=.24 ; p=.06)$.

However, in all cases differences in inhibition across the two measurements related to academic development: For math development the effect approached significance $(B=.16 ; p=.07)$. For reading and dictation, effects were significant $(B=.27 ; p<.01$ and $B=.17 ; p<.05)$. According to the log-likelihood tests, random slope did not result in model fit improvement in any of the models relating inhibition to academic development. School as a random intercept in addition to subject improved the models. Outcomes for the models with the best fit are presented in Table 3.

Table 3. Regression coefficients relating math, reading, and writing to inhibition

\begin{tabular}{|c|c|c|c|c|c|c|c|c|c|}
\hline & \multicolumn{3}{|c|}{ Number Sense Preschool - math G1 } & \multicolumn{3}{|c|}{ Rhyming Preschool - Word Reading G1 } & \multicolumn{3}{|c|}{ Emergent writing Preschool - Dictation G1 } \\
\hline & $\begin{array}{c}\text { preschool } \\
\text { number sense } \\
B(S E)\end{array}$ & $\begin{array}{c}\mathrm{G} 1 \\
\text { math } \\
B(S E)\end{array}$ & $\begin{array}{l}\mathrm{FAE}^{\mathrm{c}} \\
B(S E)\end{array}$ & $\begin{array}{c}\text { preschool } \\
\text { rhyming } \\
B(S E)\end{array}$ & $\begin{array}{c}\mathrm{G} 1 \\
\text { word reading } \\
B(S E)\end{array}$ & $\begin{array}{l}\mathrm{FAE}^{\mathrm{c}} \\
B(S E)\end{array}$ & $\begin{array}{c}\text { preschool } \\
\text { emergent } \\
\text { writing } \\
B(S E)\end{array}$ & $\begin{array}{c}\mathrm{G} 1 \\
\text { dictation } \\
B(S E)\end{array}$ & $\begin{array}{l}\mathrm{FAE}^{\mathrm{c}} \\
B(S E)\end{array}$ \\
\hline Age & $-.01(.06)$ & $-.10(.05)$ & & $.08(.04)$ & $-.05(.08)$ & & $.05(.05)$ & $-.05(.02)$ & \\
\hline Gender & $-.49(.25)$ & $.14(.21)$ & & $.46(.35)$ & $.03(.26)$ & & $.55(.26)$ & $.07(.10)$ & \\
\hline $\begin{array}{l}\text { Education } \\
\text { mother }^{\mathrm{a}}\end{array}$ & $.06(.06)$ & $.01(.05)$ & & $.16 *(.06)$ & $.02(.04)$ & & $.12(.06)$ & $.04(.04)$ & \\
\hline $\begin{array}{l}\mathrm{EF} \\
\text { (inhibition) }^{\mathrm{b}}\end{array}$ & $.38 *(.13)$ & $.22(.10)$ & $.16^{\dagger 1}(.08)$ & $.19(.16)$ & $.03(.11)$ & $.27 * *(.09)$ & $.16(.11)$ & $.05(.06)$ & $.17 *(.07)$ \\
\hline $\begin{array}{l}\text { Preschool } \\
\text { academic } \\
\text { skills }\end{array}$ & & $.41 * *(.10)$ & & & $.37 *(.12)$ & & & $.24^{\dagger 2}(.12)$ & \\
\hline
\end{tabular}

Notes.

${ }^{\mathrm{a}}$ Education $=$ highest educational level of mother (ranging from 1 to 7 ).

${ }^{\mathrm{b}}$ Using preschool score (inhibition) as predictor of preschool and Grade 1 literacy outcomes but using inhibition development (inhibition preschool - inhibition Grade 1) when predicting difference in literacy outcomes.

${ }^{\mathrm{c}}$ Fixed Effect Analysis with school as random intercept in addition to subject.

$* p<.05 ; * * p<.01 ; * * * p<.001 ;{ }^{\dagger 1} p=.07 ;{ }^{\dagger 2} p=.0$ 


\section{Discussion}

The current study aimed at testing causal relations between EF skills and academic skills. To this end we tested: 1) whether EF skills in preschool predict academic skills at the end of Grade 1 when controlling for preschool academic skills and other possible covariates, and 2) whether changes in EF are causally related to changes in academic skills from preschool to end of first grade. We found that after controlling for several covariates, executive functions at the start of preschool are mostly predictive for academic skills assessed at the same time but early delays in EF (memory and inhibition) are no longer a significant predictor of math and literacy outcomes in Grade 1. When, however, changes in EF are taken into account, EF are a moderately strong predictor of Grade 1 math, reading, and writing performance. These results indicate that EF as assessed in preschool are not a stable feature but very variable. Results thus support our hypothesis that it is important to take into account that EFs at this young age are developing. Consequently, there are no direct effects of preschool EF on reading, writing, and math skills in Grade 1. This implies that existing executive function measures are unusable as predictors of children's academic development. Young children entering preschool with delays in early EF and, because of that, in academic skills, are able to catch up in EF due to maturation, home -and school influences and maybe as a result of practicing academic skills and becoming more proficient in carrying out academic skills.

Our findings are in line with the theory that executive functions explain differences in academic development. Contrary to Willoughby's conclusion (Willoughby et al., 2012) that the relationship between EFs and academic development is spurious due to time invariant confounding variables, our results make a strong argument for a causal relation between EFs and academic skills. All relations between changes in EFs and changes in academic skills were positive, indicating that when children's EFs improve, their academic skills grow as well and conversely that when EFs skills get worse, academic skills might not improve. Even though this is not experimental evidence, it makes a strong case for the theory that learning partly depends on EFs or, vice versa, developing executive function skills depends on an increase in academic skills. The current results not only replicate but also expand those reported by Kegel and Bus (2014). Changes in EFs are a significant predictor of changes in academic skills even when there is an almost three instead of one-year time lapse. Furthermore, the current study also demonstrates that effects of EFs are not restricted to literacy development but include math development as well.

One $S D$ change in memory development coincided with about $1 / 3 S D$ change in math development and reading development, and about 1/6 SD change in writing development. Effects of inhibition on math were smaller compared to the effects of memory: $1 S D$ change in inhibition coincided with about $1 / 6 S D$ change in math. Effects of inhibition on reading and writing development were comparable with the effects of memory (1 SD change in inhibition coincided with about $1 / 3 S D$ change in reading and $1 / 6 S D$ in writing).

For all academic outcomes, both working memory and inhibition are important. For math however, memory was a stronger predictor than was inhibition. All in all, it implies that being able to maintain and manipulate information in memory and ignore distracters are essential skills for early reading and math (Diamond \& Lee, 2011). We did not find support for the hypothesis that EF have a stronger effect on math compared to literacy development (Blair \& Razza, 2007; McClelland et al., 2007). The time span in our study was wider compared to previous studies: almost three years compared to, at most, two years in earlier studies. Because emergent academic and EF skills both develop rapidly during early childhood (e.g., Davidson et al., 2006; Dehaene, 2011; Paris, 2005), a longer time span may result in greater variability in change and therefore provide a stronger test of the effect of EF development on academic development (Willoughby et al., 2012).

The finding that number sense and rhyming were substantial predictors for mathematics and reading respectively, provide enough grounds for controlling for these early academic skills when predicting academic outcomes from other factors such as EF, which is not common practice (Raghubar et al., 2010). This finding also highlights the importance of these early academic skills for formal reading and math instruction in Grade 1 (Jordan et al., 2006; Muter et al., 2004; Storch \& Whitehurst, 2002). Moreover, all academic skills correlated moderately to strongly with each other, indicating that development in mathematics tends to go together with development in reading (Davidse, de Jong, \& Bus, 2013). Compared to rhyming and number sense, emergent writing was a less strong predictor of writing in Grade 1. Scores on the emergent writing scale range from drawing figures through scribbles and random letter strings to phonetic writing (Levin \& Bus, 2003). Scores obtained on the lower levels of the emergent writing scale, as is typical for preschool age, may not have much in common with conventional writing, which may explain why writing behavior in preschool does not predict writing in first grade.

Research among teachers in the United States has indicated that teachers nowadays are more aware of the importance of EF skills for academic development and a majority mentions that they practice EF skills directly although 
intensity may differ (Morgan-Borkowsky, 2012). It is still important that teachers are aware of children who do not catch up on their EF skills during preschool and kindergarten, and as a result may not sufficiently develop their early academic skills. Additional training of EF skills might be useful for these children and should be included in early intervention programs aimed at improving early numeracy (e.g., Räsänen, Salminen, Wilson, Aunio, \& Dehaene, 2009; Siegler \& Ramani, 2009) or literacy (e.g., Bodrova \& Leong, 2007). Previous research has demonstrated that already in 4-5 years old: EF skills can improve by means of instruction (Diamond \& Lee, 2011).

In sum, the current study offers strong evidence for the hypothesis that memory and inhibition are causally related to math, reading, and writing development in kindergarten and Grade 1: Change in EF was significantly and positively related to change in all academic outcomes, whereas EF at the start of preschool did not predict Grade 1 achievement because EF skills are not a stable feature but change over time. Children with delays in EF in preschool may be able to catch up their EF skills during preschool, kindergarten and Grade 1, resulting in better performance on math, reading, and writing later on. It seems therefore important that EF skills are monitored and stimulated in school. In some cases, attention to EF skills while practicing academic skills as in the program Tools of the Mind (Bodrova \& Leong, 2007) could be beneficial and might prevent a downward spiral in children with weak EF skills. Nevertheless, training of EF should not replace training of academic skills, as there is still a debate about the transfer effects of EF training to academic skills (Melby-Lervåg \& Hulme, 2013). Our finding that preschool academic skills were moderate predictors of academic outcomes in Grade 1 after controlling for EF and other background variables indicates, in any case that it is vital to pay attention to academic skills in preschool and kindergarten.

\subsection{Limitations}

Inescapably the current study has limitations, most of which concern constraints in tests and design. Experimental manipulation, the gold standard of testing causal relations, requires that EF skills are trained separately from academic skills, and vice versa. Yet, EF skills are linked with academic skills and it may not be possible to train both separately.

A complicating factor, for long-term research, is that tests for EF and academic skills are both age-dependent and not created to demonstrate shifts over time (e.g., Blair \& Razza, 2007). They are primarily designed to make the developmental level in specific cognitive capabilities manifest. Based on the current data, we can conclude that changes in EF have to be taken into account to predict academic development. However, because of different preschool and Grade 1 tests, our findings corroborate but do not prove the theory-based inference that academic skills in Grade 1 may increase because children's EF skills improve during preschool and kindergarten.

The assessment of EF by neuropsychological tests inevitably leads to assessment of cortical-subcortical circuitry common to many forms of $\mathrm{EF}$ and by implication, behavioral functioning (Bierman, Nix, Greenberg, Blair, \& Domitrovich, 2008). To use them as measures to predict long-term development may stretch their use beyond the purpose of their original design (Wasserman \& Wasserman, 2012).

Finally, by means of FEA, stronger inferences about causality can be made (Raghubar et al., 2010), but estimates of the effects are more imprecise due to larger standard errors. Thus, although FEA reduces the risk of misleading interpretations of data, there remains some uncertainty about the strength of the effect sizes.

\section{References}

Altemeier, L. E., Abbott, R. D., \& Berninger, V. W. (2008). Executive functions for reading and writing in typical literacy development and dyslexia. Journal of Clinical and Experimental Neuropsychology, 30, 588-606. http://dx.doi.org/10.1080/13803390701562818

Bierman, K. L., Nix, R. L., Greenberg, M. T., Blair, C., \& Domitrovich, C. E. (2008). Executive functions and school readiness intervention: Impact, moderation, and mediation in the head start redi program. Development and Psychopathology, 20(03), 821-843. http://dx.doi.org/10.1017/S0954579408000394

Blair, C., \& Razza, R. P. (2007). Relating effortful control, executive function, and false belief understanding to emerging math and literacy ability in kindergarten. Child Development, 78, 647-663. http://dx.doi.org/10.1111/j.1467-8624.2007.01019.x

Blair, C., Zelazo, P. D., \& Greenberg, M. T. (2005). The measurement of executive function in early childhood. Developmental Neuropsychology, 28, 561-571. 561-571. http://dx.doi.org/10.1207/s15326942dn2802_1

Bodrova, E., \& Leong, D. J. (2007). Tools of the mind: The Vygotskian approach to early childhood education (2nd ed.). Columbus, $\mathrm{OH}$ : Merrill/Prentice Hall.

Brus, B., \& Voeten, M. (1973). Een-minuut-test handleiding [One-minute-test manual]. Nijmegen: Berkhout. 
Bull, R., Espy, K. A., \& Wiebe, S. A. (2008). Short-term memory, working memory, and executive functioning in preschoolers: Longitudinal predictors of mathematical achievement at age 7 years. Developmental Neuropsychology, 33, 205-228. http://dx.doi.org/10.1080/87565640801982312

Burrage, M. S., Ponitz, C. C., McCready, E. A., Shah, P., Sims, B. C., Jewkes, A. M., \& Morrison, F. J. (2008). Ageand schooling-related effects on executive functions in young children: A natural experiment. Child Neuropsychology, 14, 510-524. http://dx.doi.org/10.1080/09297040701756917

Clark, C. A. C., Pritchard, V. E., \& Woodward, L. J. (2010). Preschool executive functioning abilities predict early mathematics achievement. Developmental Psychology, 46, 1176-1191. http://dx.doi.org/10.1037/a0019672

Davidse, N. J., Jong, M. T., \& Bus, A. G. (2013). Explaining common variance shared by early numeracy and literacy. Reading and Writing, 27, 631-648 http://dx.doi.org/10.1007/s11145-013-9465-0

Davidse, N. J., de Jong, M. T., Bus, A. G., Huijbregts, S. C. J., \& Swaab, H. (2011). Cognitive and environmental predictors of early literacy skills. Reading and Writing, 24, 395-412. http://dx.doi.org/10.1007/s11145-010-9233-3

Davidson, M. C., Amso, D., Anderson, L. C., \& Diamond, A. (2006). Development of cognitive control and executive functions from 4 to 13 years: Evidence from manipulations of memory, inhibition, and task switching. Neuropsychologia, 44, 2037-2078. http://dx.doi.org/10.1016/j.neuropsychologia.2006.02.006

De Vos, T. (2001). Dle-test hoofdrekenen [dle-test mental arithmetic]. Drachten: Eduforce.

Dehaene, S. (2011). The number sense: How the mind creates mathematics. Revised \& expanded edition. Cambridge (UK), New York: Oxford University Press, Penguin press

Diamond, A. (2013). Executive functions. The Annual Review Of Psychology, 64, 135-168. http://dx.doi.org/10.1146/annurev-psych-113011-143750

Diamond, A., \& Talylor, C. (1996). Development of an aspect of executive control: Development of the abilities to remember what I said and to "do as I say, not as I do". Develpmental Psychobiology, 29, 315-334. http://dx.doi.org/10.1002/(SICI)1098-2302(199605)29:4<315::AID-DEV2>3.0.CO;2-T

Diamond, A., \& Lee, K. (2011). Interventions shown to aid executive function development in children 4 to 12 years old. Science, 333(6045), 959-964. http://dx.doi.org/10.1126/science.1204529

Duncan, G. J., Dowsett, C. J., Claessens, A., Magnuson, K., Huston, A. C., Klebanov, P., et al. (2007). School readiness and later achievement. Developmental Psychology, 43, 1428-1446. http://dx.doi.org/10.1037/0012-1649.43.6.1428

Espy, K. A., McDiarmid, M. M., Cwik, M. F., Stalets, M. M., Hamby, A., \& Stern, T. E. (2004). The contribution of executive functions to emergent mathematic skills in preschool children. Developmental Neuropsychology, 26, 465-486. http://dx.doi.org/10.1207/s15326942dn2601_6

Foy, J., \& Mann, V. (2013). Executive function and early reading skills. Reading and Writing, 26, 453-472. $\mathrm{http}: / / \mathrm{dx}$.doi.org/10.1007/s11145-012-9376-5

Gathercole, S. E., Pickering, S. J., Ambridge, B., \& Wearing, H. (2004). The structure of working memory from 4 to 15 years of age. Developmental Psychology, 40, 177-190. http://dx.doi.org/10.1037/0012-1649.40.2.177

Geary, D. C., Hoard, M. K., \& Hamson, C. O. (1999). Numerical and arithmetical cognition: Patterns of functions and deficits in children at risk for a mathematical disability. Journal of Experimental Child Psychology, 74, 213-239. http://dx.doi.org/10.1006/jecp.1999.2515

Griffin, S. (2002). The development of math competence in the preschool and early school years. In J. M. Royer (Series Ed.), Current Perspectives on Cognition, Learning, and Instruction: Mathematical Cognition (pp. 1-32). Greenwich, CT: Information Age.

Jordan, N. C., Kaplan, D., Locuniak, M. N., \& Ramineni, C. (2007). Predicting first-grade math achievement from developmental number sense trajectories. Learning Disabilities Research \& Practice, 22, 36-46. http://dx.doi.org/10.1111/j.1540-5826.2007.00229.x

Jordan, N. C., Kaplan, D., Olah, L. N., \& Locuniak, M. N. (2006). Number sense growth in kindergarten: A longitudinal investigation of children at risk for mathematics difficulties. Child Development, 77, 153-175. http://dx.doi.org/10.1111/j.1467-8624.2006.00862.x 
Kegel, C. A. T., \& Bus, A. G. (2013). Links between DRD4, executive attention, and alphabetic skills in a nonclinical sample. Journal of Child Psychology and Psychiatry, 54, 305-312. http://dx.doi.org/10.1111/j.1469-7610.2012.02604.x

Kegel, C. A. T., \& Bus, A. G. (2014). Evidence for Causal Relations between Executive Functions and Alphabetic Skills Based on Longitudinal Data. Infant and Child Development, 23, 22-35. http://dx.doi.org/10.1002/icd.1827

Kegel, C. A. T., van der Kooy-Hofland, V. A. C., \& Bus, A. G. (2009). Improving early phoneme skills with a computer program: Differential effects of regulatory skills. Learning and Individual Differences, 19, 549-554. http://dx.doi.org/10.1016/j.lindif.2009.07.002

Kroesbergen, E. H., Van Luit, J. E. H., Van Lieshout, E. C. D. M., Van Loosbroek, E., \& Van de Rijt, B. A. M. (2009). Individual differences in early numeracy: The role of executive functions and subitizing. Journal of Psychoeducational Assessment, 27, 226-236. 226-236. http://dx.doi.org/10.1177/0734282908330586

LeFevre, J. A., Skwarchuk, S. L., Smith-Chant, B. L., Fast, L., Kamawar, D., \& Bisanz, J. (2009). Home numeracy experiences and children's math performance in the early school years. Canadian Journal of Behavioural Science/ Revue Canadienne Des Sciences Du Comportement, 41, 55-66. http://dx.doi.org/10.1037/a0014532

Levin, I., \& Bus, A. G. (2003). How is emergent writing based on drawing? Analyses of children's products and their sorting by children and mothers. Developmental Psychology, 39, 891-905. http://dx.doi.org/10.1037/0012-1649.39.5.891

Mazzocco, M. M., \& Kover, S. T. (2007). A longitudinal assessment of executive function skills and their association with math performance. Child Neuropsychology, 13, 18-45. http://dx.doi.org/10.1080/09297040600611346

McClelland, M. M., Acock, A. C., \& Morrison, F. J. (2006). The impact of kindergarten learning-related skills on academic trajectories at the end of elementary school. Early Childhood Research Quarterly, 21, 471-490. http://dx.doi.org/10.1016/j.ecresq.2006.09.003

McClelland, M. M., Cameron, C. E., Connor, C. M., Farris, C. L., Jewkes, A. M., \& Morrison, F. J. (2007). Links between behavioral regulation and preschoolers' literacy, vocabulary, and math skills. Developmental Psychology, 43, 947-959. http://dx.doi.org/10.1037/0012-1649.43.4.947

Melby-Lervåg, M., \& Hulme, C. (2013). Is working memory training effective? A meta-analytic review. Developmental Psychology, 49, 270-291. http://dx.doi.org/10.1037/a0028228

Morgan-Borkowsly, L. (2012). Executive functions in the schools: What do teachers know about executive functions and how they impact student progress? Philadelphia College of Osteopathic Medicine, Philadelphia.

Muter, V., Hulme, C., Snowling, M. J., \& Stevenson, J. (2004). Phonemes, rimes, vocabulary, and grammatical skills as foundations of early reading development: Evidence from a longitudinal study. Developmental Psychology, 40, 665-681. http://dx.doi.org/10.1037/0012-1649.40.5.665

NICHD. (2003). Do children's attention processes mediate the link between family predictors and school readiness? Developmental Psychology, 39, 581-593. http://dx.doi.org/10.1037/0012-1649.39.3.581

Paris, S. G. (2005). Reinterpreting the development of reading skills. Reading Research Quarterly, 40, 184-202. http://dx.doi.org/10.1598/RRQ.40.2.3

Paris, S. G., \& Luo, S. W. (2010). Confounded statistical analyses hinder interpretation of the NELP report. Educational Researcher, 39, 316-322. http://dx.doi.org/10.3102/0013189X10369828

Posner, M. I., \& Rothbart, M. K. (2000). Developing mechanisms of self-regulation. Development and Psychopathology, 12, 427-441. http://dx.doi.org/10.1017/S0954579400003096

Raghubar, K. P., Barnes, M. A., \& Hecht, S. A. (2010). Working memory and mathematics: A review of developmental, individual difference, and cognitive approaches. Learning and Individual Differences, 20, 110-122. http://dx.doi.org/10.1016/j.lindif.2009.10.005

Räsänen, P., Salminen, J., Wilson, A. J., Aunio, P., \& Dehaene, S. (2009). Computer-assisted intervention for children with low numeracy skills. Cognitive Development, 24, 450-472. http://dx.doi.org/10.1016/j.cogdev.2009.09.003

Siegler, R. S., \& Ramani, G. B. (2009). Playing linear number board games-but not circular ones-improves low-income preschoolers' numerical understanding. Journal of Educational Psychology, 101, 545-560. http://dx.doi.org/10.1037/a0014239 
Storch, S. A., \& Whitehurst, G. J. (2002). Oral language and code-related precursors to reading: Evidence from a longitudinal structural model. Developmental Psychology, $38, \quad 934-947$. http://dx.doi.org/10.1037//0012-1649.38.6.934

Toll, S. W. M., Van der Ven, S. H. G., Kroesbergen, E. H., \& Van Luit, J. E. H. (2011). Executive functions as predictors of math learning disabilities. Journal of Learning Disabilities, 44, 521-532. http://dx.doi.org/10.1177/0022219410387302

Twisk, J. W. R. (2006). Applied multilevel analysis: A practical guide. . Cambridge: Cambridge University Press. http://dx.doi.org/10.1017/CBO9780511610806

Wasserman, T., \& Wasserman, L. D. (2012). The sensitivity and specificity of neuropsychological tests in the diagnosis of attention deficit hyperactivity disorder. Applied Neuropsychology: Child, 1, 90-99. http://dx.doi.org/10.1080/21622965.2012.702025

Welsh, J. A., Nix, R. L., Blair, C., Bierman, K. L., \& Nelson, K. E. (2010). The development of cognitive skills and gains in academic school readiness for children from low-income families. Journal of Educational Psychology, 102, 43-53. http://dx.doi.org/10.1037/a0016738

Willoughby, M. T., Kupersmidt, J. B., \& Voegler-Lee, M. E. (2012). Is preschool executive function causally related to academic achievement? Child Neuropsychology, 18, 79-91. http://dx.doi.org/10.1080/09297049.2011.578572

Zelazo, P. D. (2006). The dimensional change card sort (DCCS): A method of assessing executive function in children. Nature. Protocols, 1, 297-301. http://dx.doi.org/10.1038/nprot.2006.46 